\section{Amgen bulks out cardio package}

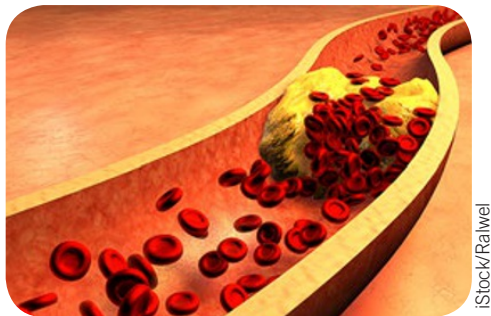

In September, Amgen announced the purchase of Dezima Pharma, a Naarden, Netherlands-based company developing an oral cholesteryl ester transfer protein (CETP) inhibitor to treat atherosclerotic cardiovascular disease. Amgen paid $\$ 300$ million in cash, in a deal potentially worth up to $\$ 1.55$ billion in development and sales milestones, to make the biotech a wholly owned subsidiary. Amgen gets Dezima's lead molecule, TA-8995, which in phase 2 trials markedly reduced lowdensity lipoprotein cholesterol (LDL), both as monotherapy or in combination with statins. Amgen's cardiovascular disease portfolio includes Corlanor (ivabradine) and Repatha (evolocumab), one of two recently approved PCSK9 inhibitors, with expected sales of \$2-4 billion annually. By adding TA-8995 to its portfolio, the Thousand Oaks, California-based biotech expects to offer more treatment options with different mechanisms of action and modes of administration across varying LDL-cholesterol levels and risk profiles, said Amgen's executive vice president of R\&D Sean Harper. Dezima originally licensed rights to TA-8995 from Mitsubishi Tanabe Pharma. The news was followed by an October announcement by Eli Lilly that it will halt all trials of CETP inhibitor evacetrapib in the same indication. Lilly's CEPT inhibitor, in phase 3 clinical trials, measured LDL-cholesterol reduction in patients with high cholesterol, but a data monitoring committee recommended terminating the trial because there was a "low probability the studies would meet their endpoint."

\section{6 "Are genomes going to be so democratized and unregulated that we create an entirely fraudulent} industry around them?" Robert C. Green, clinical geneticist at Harvard Medical School, commenting on the lack of knowledge about the clinical relevance of many genetic variants. Such concerns led the American College of Medical Genetics and Genomics to compile a list of variants that should not be tested. (The Washington Post, 11 September 2015)

"What I object to is a lack of complex evaluations of the technology, the overzealous selling of its benefits and the framing of cautionary skeptics as antiscience scaremongers." Maywa Montenegro, food systems researcher at UC Berkeley, who is not anti-GMO, calls for a new conversation on GMOs. (Ensia, 7 October 2015)

\section{UK funding agencies weigh in on human germline editing}

On September 2, five prominent UK biomedical research funding bodies issued a joint statement supporting the use of CRISPR-Cas9 and other genome editing techniques in research, including human reproductive cells and early embryos. Weeks later, stem cell scientist Kathy Niakan at the Francis Crick Institute in London applied for a license from the Human Fertilization and Embryology Authority (HFEA) to use new genome editing techniques based on CRISPR-Cas9 on human embryos. The HFEA, a body created to regulate fertility treatment and embryo research, confirms that if granted this will be the first gene-editing license using CRISPR-Cas9 for research issued by a national regulator.

The powerful CRISPR-Cas9 editing system (Nat. Biotechnol. 33, 429, 2015) and its wide adoption lent urgency to the debate over human germ cell modification. In particular, a publication by Chinese scientists in Protein \& Cell using CRISPR-Cas9 in early, nonviable human embryos $(6,363-372,2015)$ caused consternation. Discussions are now ongoing within the global scientific community around where to draw the line between acceptable and unacceptable uses of these technologies for human germline alternation (Nat. Biotechnol. 33, 478-486, 2015).

The UK's coalition of funding bodies reacted swiftly and reached a consensus. The group felt it important to "make clear to researchers that we'll continue to fund research that is permissible under current [UK] regulations," says Katherine Littler, senior policy advisor at the Wellcome Trust. "We're not calling for those regulations to change," Littler emphasizes. The UK, through the HFEA's Act of 1990, already allows research in human embryos up to 14 days old when performed under licenses.

The group issued the statement because they were concerned that a knee-jerk reaction to the Chinese study would result in a moratorium banning all germ cell editing under any circumstances. "I don't think that's how you do good science," says Peter Braude, emeritus professor of obstetrics and gynecology at King's College, London, and Fellow of the Academy of Medical Sciences, one of the statement's signatories.

The coalition declared it will continue to fund the use of CRISPR-Cas9 and other genomeediting techniques in both somatic and germline cells, where this is ethically justifiable and within the law. Justified uses might include research leading to significant progress in understanding key biological processes.

The UK's highly consultative manner in dealing with these technologies in the past may help explain the lack of controversy leading up to the statement. Over the last two decades, reproductive issues including mitochondrial donation for in vitro fertilization therapy, have been resolved in consultation with the HFEA, and sometimes discussed in Parliament's House of Lords. "We have clear legislation that has reached across all activities in the UK, and have had informed debate in this general area for a number of years," says Robin Buckle, director of science programs at the UK Medical Research Council, one of the statement's co-signatories. "The UK scientists' statements show a balanced, informed view of

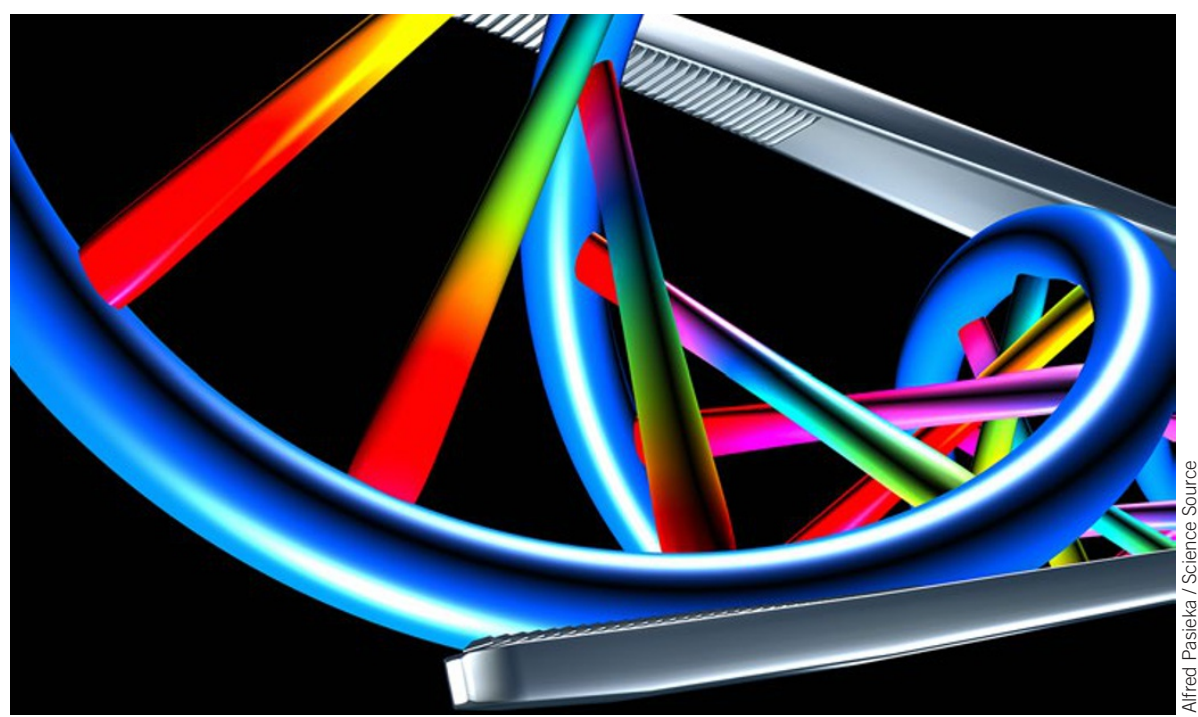

DNA tweezers: regulations over the use of human genome editing techniques in embryos vary from country to country. 